European Journal of STEM Education, 1:3 (2016), 56

ISSN: $2468-4368$

\title{
Investigating Children's Multiplicative Thinking: Implications for Teaching
}

Chris Hurst ${ }^{1 *}$, Derek Hurrell ${ }^{2}$

${ }^{1}$ Curtin University, AUSTRALIA

${ }^{2}$ University of Notre Dame, AUSTRALIA

*Corresponding Author: c.hurst@curtin.edu.au

Citation: Hurst, C. and Hurrell, D. (2016) Investigating Children's Multiplicative Thinking: Implications for Teaching, European Journal of STEM Education, 1:3 (2016), 56.

doi: http://dx.doi.org/10.20897/lectito.201656

Received: May 24, 2016; Accepted: June 23, 2016; Published: December 29, 2016

\begin{abstract}
Multiplicative thinking is a 'big idea' of mathematics that underpins much of the mathematics learned beyond the early primary school years. This article reports on a recent study that utilised an interview tool and a written quiz to gather data about children's multiplicative thinking. Our research has so far revealed that many primary aged children have a procedural view of multiplicative thinking which we believe inhibits their progress. There are two aspects to this article. First, we present some aspects of the interview tool and written quiz, along with some of findings, and we consider the implications of those findings. Second, we present a key teaching idea and an associated task that has been developed from our research. The main purpose of the article is to promote the development of conceptual understanding of the multiplicative situation as opposed to the teaching of procedures. In doing so, we encourage the explicit teaching of the many connections within the multiplicative situation and between it and other 'big ideas' such as proportional reasoning and algebraic thinking.
\end{abstract}

Keywords: multiplicative thinking, arrays, factors, multiples, interviews

This article has been developed from two papers written and presented by the authors, and published in the proceedings of the 52nd annual conference of the Mathematical Association of Victoria (MAV), Back to the Future, Melbourne, December 3-4, 2015.

\section{BACKGROUND}

The importance of multiplicative thinking as a 'big idea' of mathematics has been well documented (Siemon, Bleckly, \& Neal, 2012; Siemon, Breed, Dole, Izard, \& Virgona, 2006), as has the importance of 'big ideas' in highlighting the myriad connections within and between them (Charles, 2005; Clarke, Clarke, \& Sullivan, 2012). Charles (2005) asserted that 'big ideas' "link numerous mathematical understandings into a coherent whole", and make connections, and that "good teaching should make those connections explicit" (p. 10). Multiplicative thinking is one such 'big idea'.

Multiplicative thinking is vitally important in the development of significant mathematical concepts and understandings such as algebraic reasoning (Brown \& Quinn, 2006), place value, proportional reasoning, rates and ratios, measurement, and statistical sampling (Mulligan \& Watson, 1998; Siemon, Izard, Breed \& Virgona, 2006). Further, Siegler et al. (2012) advocate that knowledge of division and of fractions (another part of mathematics very much reliant on multiplicative thinking) are unique predictors of later mathematical achievement. 


\section{The Difficulties inherent in Multiplicative Thinking}

Unfortunately, research (Clark \& Kamii, 1996; Siemon, Breed, Dole, Izard, \& Virgona, 2006) has found that the label of being 'solid' multiplicative thinkers cannot be applied to most students. Clarke and Kamii (1996) found that $52 \%$ of fifth grade students were not 'solid' multiplicative thinkers, and Siemon, Breed, Dole, Izard, and Virgona (2006) established that up to $40 \%$ of Year 7 and 8 students performed below curriculum expectations in multiplicative thinking, with at least $25 \%$ well below the expected level.

Whereas most students enter school with informal knowledge that supports both counting and early additive thinking (Sophian \& Madrid, 2003) students need to re-conceptualise their understanding about number to understand multiplicative relationships (Wright, 2011). Multiplicative thinking is distinctly different from additive thinking even though it is constructed by children from their additive thinking processes (Clark \& Kamii, 1996). The difference between additive thinking and multiplicative thinking has been characterised by Confrey and Smith (1995) as the difference between a "counting world" and a "splitting world". Essentially a "splitting world" is the ability to share (split) and is an idea to which many students are very sensitive from their earliest experiences (Confrey, 1994). Therefore, this makes splitting part of the multiplicative situation. The position taken in this paper is that multiplication and division are two ways of describing the same situation. In order to help students understand the connection, it may be helpful to represent division as multiplication more often than is currently done. For example, if a simple exercise is considered - If 42 sweets are shared equally among six children, how many does each person receive? - It is suggested that this could be shown as $6 \times \ldots=42$, to reinforce the multiplicative situation as an exercise is 'splitting'. The counting world however, identifies additive increments and often 'interferes' with the splitting concept. The counting world does not lead students' thinking into the world of rational numbers (fractions, percentages ratios etc.) in the same way as the splitting world does (Confrey \& Smith, 1995).

If teachers are to make explicit the many links and connections within the splitting world (multiplicative situation), and allow students to develop a conceptual understanding of this, rather than focus solely on the Content Strands (Number and Algebra, Measurement and Geometry, Statistics and Probability), they should emphasize the Proficiency Strands (particularly Reasoning and Problem Solving) of the Australian Curriculum: Mathematics (Australian Curriculum, Assessment \& Reporting Authority, 2015). Instead of teaching children a set of 'rules' for working with numbers, and teaching ideas like multiplication and division as separate entities, more effective teaching would focus on reasoning about why numbers behave as they do when operating, and understanding how multiplication and division are different ways of describing the same situation. Other curriculums have parallels to the Australian Proficiency Strands. In the United States, the Common Core State Standards for Mathematics (NGA Centre, 2010) contain similar profound statements called Standards for Mathematical Practice. These include a discussion of 'reasoning abstractly and quantitatively' and a description of 'quantitative reasoning' that "entails habits of creating a coherent representation of the problem at hand [and] attending to the meanings of quantities" (NGA Centre, 2010, p. 6.)

This article describes two parts of an on-going study conducted with over 400 primary aged children to determine the extent of their multiplicative thinking. The results of the study are interesting in themselves, however, it is the inferences that can be drawn about teaching and the associated implications for teaching about multiplicative thinking that comprise the main thrust of this article.

Two underpinning aspects of multiplicative thinking were identified by the researchers as being central to conceptual development. First, the concept of equal groups and the multiplicative array are seen as powerful ways of representing the multiplicative situation (Jacob \& Mulligan, 2014; Young-Loveridge, 2005) as they enable children to articulate their understanding of the property of commutativity, as well as the inverse relationship between multiplication and division. Second, the language of factors and multiples enables children to explain such ideas (Hurrell \& Hurst, 2016). The specific research question on which this article is based is as follows:

- To what extent do upper primary children understand multiplicative arrays, the concept of equal groups, and the language of factors and multiples, and use these ideas to articulate their understanding of the multiplicative situation and related ideas such as the inverse relationship and the commutative property?

\section{RESEARCH METHODOLOGY}

As noted earlier, the research reported upon here is part of a larger current study into primary/elementary school aged children's multiplicative thinking. This article deals with the first phase of the project and the data derived from that phase. 


\section{Participant characteristics}

The results and discussion which follow are presented in two sections, based on two different parts of the sample. Section 1 involved students from two different schools. School A had an Index of Community SocioEconomic Advantage (ICSEA) ranking of 1082, with a ranking of 1000 being considered as average. School B's ICSEA ranking was 1063. None of the students in the sample from either school was from an English as Second Language (ESL), or Indigenous background and no student in either sample suffered from a disability or specific learning difficulty. Hence the samples could be described as comparable. All parents of the students were provided with information letters about the project. Consent forms were returned for 22 students in School A and 16 students in School B who consequently formed the sample. That is, the researchers included all students (38) for whom a consent form was received. The semi-structured interview instrument was administered with these students. This will be described shortly.

Section 2 involved students from School C which had an ICSEA ranking of 1047. School C had no Indigenous students and 36\% of the student population came from an ESL background. Similar to the sample from Schools $\mathrm{A}$ and $\mathrm{B}$, no student suffered from a disability or specific learning difficulty. All students in each of the three Year 4, 5 and 6 classes comprised the sample $(n=180)$ and the written Multiplicative Thinking Quiz (MTQ) was administered with these students. This will be described shortly. In each sample from Schools A, B, and C, the participants' classes were taught by a home-room teacher or generalist, not by a specially trained primary mathematics teacher (Hurrell \& Hurst, 2016).

\section{Selection of participants}

The principals of the three schools had expressed an interest in their schools being involved in the research project which sought to understand the capacity of primary (or elementary) aged children to think multiplicatively. To begin the project, the researchers planned to gather data solely from Year 6 students but the principals of Schools A and C expressed an interest in involving their Year 5, and Years 4 and 5 students respectively, and the decision was taken to widen the age limits of the sample. This enabled the researchers to identify differences in thinking between different year levels that would inform the later phases of the project.

\section{Data gathering}

There were two instruments used to gather data, a semi-structured interview and a written quiz. Semi-structured interviews were conducted with 38 children in Years 5 and 6 in two different schools (Schools A and B). Interviews lasted between 25 and 40 minutes. A questionnaire was developed from the interview format in order to generate a larger set of data in a shorter time. The questionnaire was administered to nine complete class groups comprising 180 children in Years Four, Five and Six at the third school (School C) and the administration of the questionnaire took about 30 minutes per group. Both the questionnaire and interview were administered to the Year 5 group at School A to establish the consistency of the results from the questionnaire. Whilst the data from the questionnaire was shown to be consistent with those from the interview, richer data were generated from the interview. Burns (2010) asserts that the power of the interview lies in the quality of the question posed by the interviewer or teacher. Examples include "Can you explain how you worked that out?" and "How did you get that answer?" irrespective of whether the child interviewee had the correct answer or not.

Each interview was attended by two researchers, one of whom posed questions while the other wrote anecdotal notes. Interviews were conducted in a quiet open area adjacent to classrooms and lasted around 30 to 35 minutes. In order to provide an opportunity for clarification and deeper reflection on what was said about the mathematics, interviews were audio-recorded for the purpose of later transcription. In order to ensure consistency, the same researcher asked the interview questions on each occasion, using a prepared script. A debriefing session was conducted by the researchers immediately following each interview in which they clarified their thinking and posed questions of each other about participant responses from the interview. This was done to provide a greater level of inter-rater reliability. Both researchers accessed the audio recordings and one of them compiled a detailed analysis of each interview which was then cross-checked by the second researcher (Hurrell \& Hurst, 2016).

The written quiz (MTQ) and interview contained the same questions based around key aspects of multiplicative thinking. The strength of the interview lay in the fact that an initial question could be asked and then, depending on the response of the student, followed up with more probing questions. Materials such as counters, bundling sticks, pen/paper, calculator, and Multibase Arithmetic Blocks (MABs) were provided for the interview. Only the interview and quiz questions relevant to the research question stated earlier are included here and shown below.

\section{Part 1}

These questions probe participants' understanding of the multiplicative situation, that one number represents the number of equal groups and the other represents the number in each of the equal groups. As well, the second 
question seeks to find out if students use a multiplicative array or a number of separate groups to represent a number fact.

- What do the numbers in the number sentence $7 \times 6$ tell you?

- Please use some of the counters to show what is happening in $4 \times 3$.

$\circ \quad$ Can you show me in a different way?

\section{Part 2}

This probes participants' knowledge and use of the key mathematical language of factors and multiples and if they can articulate their understanding clearly.

- Can you tell me what a 'factor' and 'multiple' of a number is?

- In $4 \times 3=12$, which numbers are factors and multiples?

- Can you tell me some factors and multiples of 20 ?

\section{Part 3}

This section seeks to understand the extent of participants' understanding of the inverse relationship between multiplication and division and the commutative property, and how they articulate that understanding.

- My friend Paul says if you know that $17 \times 6=102$, you can work out the answer to $102 \div 6$ ? Is he correct?

- My friend Paul says if you know the answer to $17 \times 6$, you can work out the answer to $6 \times 17$. Is he correct?

These questions were chosen because they explore key aspects of multiplicative thinking, the understanding (or otherwise) of which is likely to provide an indication of a student's level of thinking.

Consistent with ethics requirements, all participants were free to withdraw from the project at any stage (Hurrell \& Hurst, 2016). The researchers wanted to complete the data gathering process promptly to avoid any potential validity issues with the data such as 'maturation threats' or 'history threats' (Fraenkel \& Wallen, 2003). Similarly, no more than four interviews were conducted on any given day to avoid other potential threats to validity such as 'instrument decay' (Fraenkel \& Wallen, 2003; Hurst \& Hurrell, 2016). Due to the fact that the sample size is relatively small, it is not possible to make substantial generalisations about children's knowledge. Rather, the purpose of this article is to point out some aspects of some children's thinking and the inferences that might be drawn from them. As noted the research reported upon here is part of a current and larger project, one aspect of which includes the interviewing of a larger cohort of students to see if such generalisations might be possible.

\section{RESULTS AND DISCUSSION}

The responses from the interviews and questionnaires made for some interesting overall observations. First, responses from the Year Five cohort at School A and the Year Six cohort at School B revealed a wide range of conceptual understanding. Second, responses to the questionnaire administered at School C revealed that the three class groups within each year level had varying levels of understanding. While there were large variations within each year level, a similar range was evident between year levels, and indeed, within each class group. This paper suggests that the differences may have resulted, at least to some extent, from different pedagogies, teaching styles, and/or may reflect different stages of development of children's understandings of multiplicative concepts. After all, Siemon et al. (2011) have noted that multiplicative thinking usually does not fully develop until the early secondary years.

\section{Section 1: School A and School B}

The purpose of this paper is not to compare performance of different school cohorts against one another or different sections of school cohorts against one another. Rather it seeks to identify aspects of multiplicative thinking that might be evident or otherwise in different children and to understand why that might be so. Hence interview results from Schools A and B are combined into one set. Table 1 presents a summary of responses to the five illustrative questions listed above for the Year Five cohort from School A and the Year Six cohort from School B ( $\mathrm{n}=38)$.

It is also worth noting that of the 38 children in the combined sample, ten (26\%) responded correctly to four or five of the above questions and a further seven $(18 \%)$ responded correctly to three of the questions. This seems to indicate that approximately one quarter of the sample demonstrated a strong level of conceptual understanding of the selected aspects of multiplicative thinking and a smaller proportion showed a reasonable level of understanding. However, over half the children in the sample could only respond appropriately to two or less of the selected questions. This points to a wide range of understanding across the sample. These findings are congruent with the percentages of students who struggle with multiplicative thinking (Clarke \& Kamii, 1996; Siemon et al., 2006), as described earlier. 
Table 1. Summary of Responses from Schools A and B

\begin{tabular}{lc}
\hline Mathematical understanding demonstrated by responses to listed questions & School A Year 5 \\
School B Year 6
\end{tabular}

\section{Some typical strong responses}

Typical responses demonstrating a strong level of conceptual understanding of the commutative property of multiplication include the following:

Student Dylan - "It doesn't really matter which way it is - seventeen groups of six is the same as six groups of seventeen". He then used tiles to make three groups of five and five groups of three, and also rearranged twelve tiles saying "I just put them into a three by four grid - it's the same as a four by three".

Student Dean - "It's just the same ... you just flip it around". He then used tiles to make a three by five array and rotated the array to explain his point.

Similarly, the following exchange during the interview with Student Jason shows some connection of ideas around the inverse relationship between multiplication and division, sharing into equal groups, and arrays.

When discussing the division fact $24 \div 3$, Jason showed it as an array and said, "Then I'm going to split it up into threes, because I'm going to see how many groups of three I can have in 24". Also said, when asked what the answer would be, "I started with knowing that how many threes go into 15 and that's five, then I counted by threes to get 18, 21, 24". He also said, "If I had 3 times 4 it would be 12 . If I had 12 divided by 3 it would be 4 ". He also gave a similar example with " 8 groups of $3=24$, so $24 \div 8=3$ "

Such connected discussion seems to demonstrate a sound understanding of the concepts involved.

\section{Responses indicating partial understanding}

The apparent lack of conceptual understanding in the responses of some children is of interest. It is difficult to draw conclusions about the depth of some children's conceptual understanding given the absence of links and connections between responses to different questions. That is, some children show some understanding of a particular idea which might lead one to reasonably expect they would show an understanding of related concepts. However, this was often not the case.

It is well accepted that the array is a powerful representation of the multiplicative situation (Jacob \& Mulligan, 2014). However, while two of the children (Ellie and Tilly) drew an array to represent the given number fact, neither of them could explain why the commutative property works, in terms of the array. Rather, they said that the numbers were 'swapped around' (Tilly) or 'you've just swapped them around' (Ellie). Tilly and Ellie and other students like them could not articulate why you could 'swap' the numbers around, and it appeared that they had developed a procedural, perhaps even rote, response to the question, rather than one with an underlying conceptual understanding. Also, of the thirteen children who drew an array, only seven of them could describe factors and multiples.

Similarly, while $63 \%$ of the children $(n=24)$ could adequately describe factors and multiples and their roles in the multiplicative situation, only five of them talked about the $7 \times 6$ number fact in terms of group size and number of groups. Further to that, $39 \%$ of the children $(n=15)$ described the number fact in terms of group size and number of groups, yet only five of that group also drew an array. Some of the children $(\mathrm{n}=11)$ adequately explained the commutative property and half $(n=19)$ explained the inverse relationship between multiplication and division. However, not all of the eleven children who explained the commutative property could also explain the inverse relationship. This is interesting because the ideas underpinning those interview tasks are inextricably linked - that is, group size/number, the factor-factor-multiple relationship, the representation as an array, the commutative property, and the inverse relationship. Hence, it might be reasonably expected that there would be more children who could perform well on all or most of the items, or on none (or very few) of them.

\section{School A and B Implications}

The inferences that can be drawn from the School A and B data suggest that the connections between those important ideas need to be made clear and more explicit so that a mutual understanding of them can be developed. This is supported by the observations that: some students drew an array; some others could explain factors and multiples; and some others could explain a multiplication fact in terms of group size and number. Perhaps it is because there had been passing mention made of these key ideas, rather than sustained and explicit teaching of 
Table 2. Comparison of Responses from Different Year Levels at School C

\begin{tabular}{lccc}
\hline Mathematical understanding demonstrated by responses to listed questions & Year 4 & Year 5 & Year $\mathbf{6}$ \\
\hline Identifies numbers in multiplication fact as 'group size' and 'number of groups'. & $14 \%$ & $9 \%$ & $23 \%$ \\
\hline Represents given multiplication fact as an array. & $28 \%$ & $32 \%$ & $39 \%$ \\
\hline $\begin{array}{l}\text { Defines 'factor' and 'multiple' and/or identifies factors and multiples in given number } \\
\text { fact. }\end{array}$ & $3 \%$ & $15 \%$ & $14 \%$ \\
\hline $\begin{array}{l}\text { Explains commutative property in a conceptual way and/or demonstrates it using an } \\
\text { array. }\end{array}$ & $0 \%$ & $2 \%$ & $5 \%$ \\
\hline $\begin{array}{l}\text { Explains inverse relationship in a conceptual way based on number of groups and } \\
\text { group size }\end{array}$ & $10 \%$ & $1 \%$ & $12 \%$ \\
\hline
\end{tabular}

Table 3. Comparison within Year Levels in School C

\begin{tabular}{lccc}
\hline Mathematical understanding demonstrated by responses to listed questions & 4A & 4B & 4C \\
\hline Identifies numbers in multiplication fact as 'group size' and 'number of groups'. & $0 \%$ & $6 \%$ & $35 \%$ \\
\hline $\begin{array}{l}\text { Represents given multiplication fact as an array. } \\
\begin{array}{l}\text { Defines 'factor' and 'multiple' and/or identifies factors and multiples in given } \\
\text { number fact. }\end{array}\end{array}$ & $62 \%$ & $17 \%$ & $0 \%$ \\
\hline $\begin{array}{l}\text { Explains commutative property in a conceptual way and/or demonstrates it using an } \\
\text { array. }\end{array}$ & $0 \%$ & $6 \%$ & $5 \%$ \\
\hline $\begin{array}{l}\text { Explains inverse relationship in a conceptual way based on number of groups and } \\
\text { group size }\end{array}$ & $14 \%$ & $0 \%$ & $0 \%$ \\
\hline
\end{tabular}

them. For example, the fact that less than one third of the children could explain the commutative property in a conceptual way gives rise to questions about how the commutative property may have been taught. Perhaps it is also attributable to the fact that children's understanding of the multiplicative situation is developing and in a state of flux. After all, it has been noted (Siemon et al., 2011) that multiplicative thinking is a concept that does not fully develop until around the age of fourteen and the students involved here are several years younger than that.

The lack of sustained teaching may also be because the teachers simply do not appreciate the critical importance of the ideas of factor/multiple, group size/number, and the use of the array. Hence they may have taught some of the ideas once, assuming that such limited exposure was appropriate when the evidence would suggest otherwise.

\section{Section 2: School C}

In School C, the questionnaire was administered to 180 children in Years Four, Five and Six. Table 2 represents the responses from the three year levels in School C to questions about the same concepts as shown in Table 1.

In general, it would probably be expected that the Year Six children would perform better than the Year Five children who would in turn perform better than the Year Four children. However, as can be seen, this is not always the case and even where it is, one would perhaps expect the comparative performance of the older children to be markedly better than it is.

Of more interest is the comparison within each year level in School C, as shown in Table 3 which shows responses from children in the three Year Four classes. Here, there are marked differences in the responses from different class groups, particularly in relation to the first two questions.

It is noteworthy that no child in Class $4 \mathrm{~A}$ could identify 'group size' and 'number of groups' in multiplication facts when over a third $(35 \%)$ of Class $4 \mathrm{C}$ could do so. Even more intriguing is that nearly two thirds $(62 \%)$ of Class 4A drew an array to show a multiplication fact when not one child in Class 4C did that. As well, very few children in Class 4B responded correctly on any of the five questions. What might this indicate?

\section{School C Implications}

Classes at School $\mathrm{C}$ are not streamed on ability. Hence, it seems reasonable to assume that the variation in responses may be due to different teaching occurring among the three Year Four classes. Perhaps there has been a clear emphasis in Class 4A on the use of arrays, rather than showing multiplication facts as separate groups. It is also worth noting that the responses from Class $4 \mathrm{~A}(62 \%)$ to the array question were the highest of any class in the school - only one Year Six class (53\%) and one Year Five class (50\%) recorded a similar level of correct responses. Similarly, the teaching in Class $4 \mathrm{C}$ is likely to have emphasized the notion of 'group size' and 'number of groups' in the multiplicative situation. Again, Class 4C's response (35\%) is the highest recorded of all classes with only one Year Six class (33\%) recording a similar level of correct answers. What is not apparent across these classes, nor across Schools A and B, is explicit, sustained teaching of the connections between the five related ideas in the multiplicative situation. 


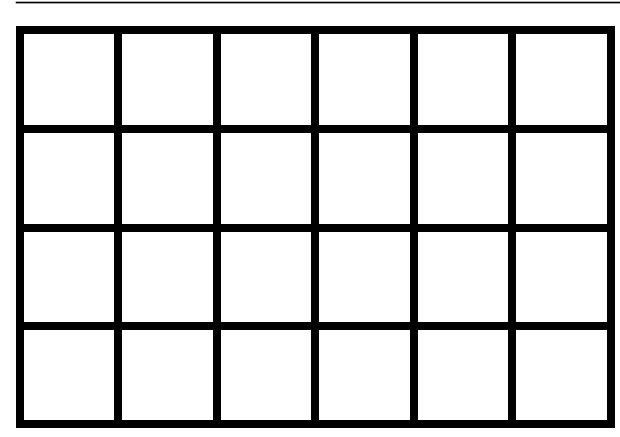

Figure 1. Multiplicative array

\section{MULTIPLICATIVE THINKING: WHAT HELPS STUDENTS?}

If, as the research tells us, multiplicative thinking is vital for further success in mathematics, but difficult to learn, then teachers need the content and pedagogical knowledge to succeed in their endeavours to effectively teach it. Carroll (2007) has constructed a list of strategies and ideas that support multiplicative thinking, as well as some pedagogical issues about which teachers need to be aware.

- Allow children to work out their own ways to solve problems involving multiplicative thinking.

- Compare additive and multiplicative thinking approaches.

- Use models that clearly illustrate the idea/s.

- Sometimes students are introduced to the ideas symbolically before the groundwork has been done to establish meaning and become comfortable in working with them.

- Make and discuss the links between fraction ideas, rates, ratios and proportion.

- Use authentic contexts and models to exemplify situations.

- Estimation is really important as it demonstrates understanding of the concepts involved.

- Engage in conversations about the ideas and talk about the links, discuss the similarities and differences between the ideas.

- It is development of fuller, deeper and more connected understandings of the number system that makes a difference.

Carroll (2007, pp. 41 - 42)

In the remainder of this article we would like to pursue dot point three of Carroll's (2007) list; "Use models that clearly illustrate the idea/s". Although this will be the focus, it should be noted that by carefully considering the model used to 'carry' the understanding, at one time or another, the remainder of Carroll's list should be exercised.

\section{A MODEL FOR THE DEVELOPMENT OF MULTIPLICATIVE THINKING}

One model for trying to build a conceptual understanding of multiplication is the multiplicative array. Multiplicative arrays refer to representations of rectangular arrays in which the multiplier and the multiplicand are exchangeable (Figure 1). These arrays are seen by some as powerful ways in which to represent multiplication (Barmby, Harries, Higgins \& Suggate, 2009; Young-Loveridge \& Mills, 2009). Young-Loveridge (2005) asserts that multiplicative arrays have the potential to allow students to visualise commutativity, associativity and distributivity. Further, Wright (2011) states that multiplicative arrays embody the binary nature of multiplication, and that as a representation, they have value, as they also connect to ideas of measurement of area and volume and Cartesian products. We will visit the use of multiplicative arrays in the activity called "A bag of tiles."

\section{Task - A Bag of Tiles}

This task can be varied to suit the teaching and learning of several aspects of multiplicative thinking. Essentially it is based on students working with a set of $2 \mathrm{~cm} \times 2 \mathrm{~cm}$ plastic tiles. These can be given out in a plastic snap-lock bag and can vary in number, depending on the task and the targeted aspect of multiplicative thinking. However, for the following activity each pair of students is given 24 tiles. Although each student could be given their own set of tiles, if we want the students to engage in meaningful conversations about the task and about the multiplicative thinking behind the task, then having the students in pairs is actually a more productive setting. 
Rectangle B

Rectangle A

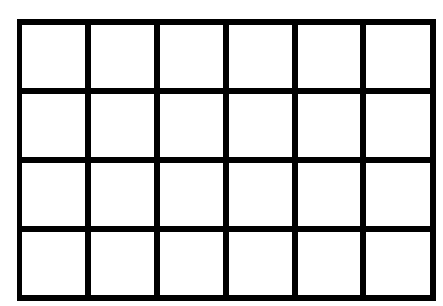

Rectangle $A$ is different to Rectangle B

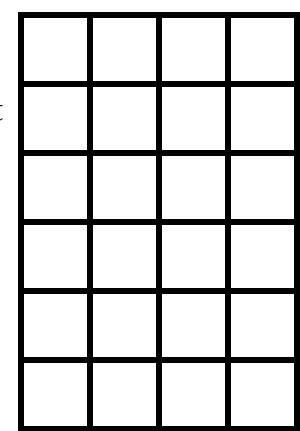

Figure 2. Two "different" rectangles, $6 \times 4$ and $4 \times 6$
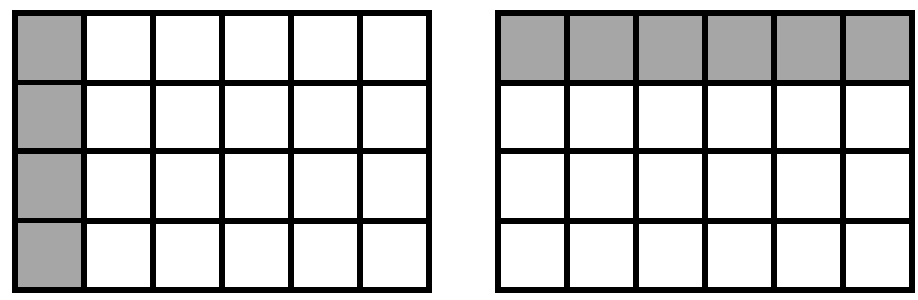

Figure 3. Overlaying Rectangle A with different strips

The basic task is for children to make an array with the tiles so that rows and columns contain the same number of tiles with none left over. In this case one array which might be produced is a $6 \times 4$ configuration. The choice of 24 is worthy of note as it can also result in arrays of $8 \times 3$ or $3 \times 8$ ), $12 \times 2$ (or $2 \times 12$ ), and of course $24 \times 1$ (or $1 \times 24)$. The different arrays A and B (Figure 2) provide an interesting discussion point in leading children to a realisation that although the two arrays arrive at the same total, the manner in which they are constructed is important in certain contexts. For instance, there may be very big ramifications in not understanding that, although in a day you would end up taking twelve tablets, taking two tablets, six times a day may have very different effects from taking six tablets twice a day. This idea can be further developed by asking children to 'tell a story' about each number fact to show that $4 \times 6$ (four rows of six) is indeed different to $6 \times 4$ (six rows of four). The notion of 'story telling' invokes Carroll's (2007) points regarding discussions and conversations, and authentic contexts.

As well, the two arrays offer a good opportunity to develop an understanding of the commutative property in a deeper way that by simply rotating the array. Different coloured strips of four and six squares can be laid over the array to show that while the two arrays represent the same product, they are in fact different (Figure 3). That is, four yellow strips of six cover the array in the same way as do six green strips of four. The result is the same but the situation is different and this is the essence of understanding the commutative property.

The students are then asked to find all of the different rectangles that can be made from 24 tiles. The bag of tiles activity works very well as a physical representation to develop an understanding of factors and multiples as well as the commutative property of multiplication, both very powerful understandings which will be often called upon in mathematics. This is also a good opportunity to make connections between the representations of the arrays and the way we symbolically record them. Further we can exploit the opportunity to discuss and show the links within the multiplicative situation (i.e., the inextricable relationship between multiplication and division, being, $6 \times 4=24,4 \times 6=24,24 \div 6=4$ and $24 \div 4=6$, as well as the division construct for fractions). Over and above the mathematical content that this activity contains, it also embodies the four proficiency strands (Problem Solving, Understanding, Reasoning and Fluency) as articulated in the Australian Curriculum: Mathematics (ACARA, 2015). There are also clear links to the Common Core State Standards for Mathematics where the Standards for Mathematical Practice include discussion of the notion of "looking for and making sense of structure" (NGA Centre, 2010, p. 6).

Further to the richness that can be gleaned from using 24 tiles and asking the questions that are articulated above, the same activities can be entered into with arrays of other sizes to further develop and re-inforce the understandings. The tiles can then be employed to investigate prime, composite, square and triangular numbers.

For example, to develop an understanding of prime and composite numbers, the students are given more tiles to work with, and are instructed that they cannot rotate the tiles (employ the commutative property) and still consider them to be 'different'. Therefore, a $6 \times 4$ configuration is considered to be the same as a $4 \times 6$ configuration. They are then asked see if they can make a rectangle with two tiles in more than one 'different' way? They build the array and record the finding that the only configuration for two tiles is a $2 \times 1$ array. The students 


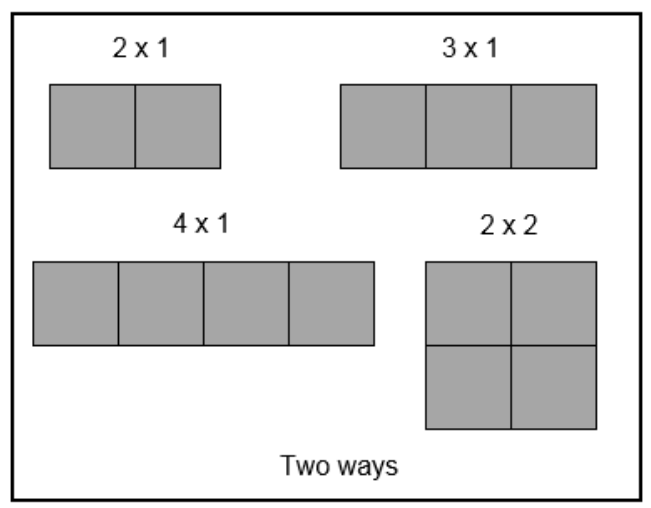

Figure 4. Arrays for 2 tiles, three tiles and four tiles

then investigate three tiles and continue their investigations as required, but probably for not less than the 24 tiles with which they started (Figure 4). There is a conversation to be had with first of all, four tiles, and then with nine tiles, and then 16 tiles (possibly even 25 tiles) about whether a square is a rectangle.

Initially what the students are making and recording are the factors for whole numbers between two and 24. What is also occurring, is an opportunity to talk about the numbers for which two or more sets of factors cannot be found (prime numbers) and the numbers which have multiple sets of factors (composite numbers). The exploration here of course is what makes some numbers prime numbers and others, composite numbers. Also, by previously considering arrays for the numbers four, nine, 16 and perhaps 25 , an exploration of square numbers and why we call them square numbers can be undertaken.

\section{GENERAL IMPLICATIONS}

The five selected questions from the interview and questionnaire represent less than a quarter of the full instrument yet the data generated from just three sets of children have provided plenty of food for thought. There are two main observations that can be made from the presented data. First, there are considerable differences in the levels of understanding of multiplicative concepts shown by two groups (Schools A and B) that were interviewed. Some children displayed more connected understanding than did others. Second, there is considerable difference in responses among classes in the same year level at the same school (School C) where the questionnaire was administered. In seeking reasons for this, it is reasonable to infer that the differences may be due to pedagogies.

The differences in responses are quite stark at times and the relative connectedness in the thinking of some children in the combined cohort from Schools A and B suggests that connections between ideas may have been made more explicit in some classes compared to others. This raises the question of the level of opportunity that students have in their classroom to engage in problem solving and reasoning when developing multiplicative thinking and perhaps other areas of mathematics. Also, in responding to questions other than those reported here, some children were reluctant and/or unable to depart from quite procedural responses which was not the case with other children.

\section{CONCLUSIONS}

In this article we have only just begun to explore the opportunities afforded by multiplicative arrays to support students in understanding the multiplicative situation. Arrays can also be used to link to the division construct for fractions - e.g., a group of twenty four tiles can be split into quarters so that one quarter of 24 is 6 , two quarters of 24 is 12, three quarters of 24 is 18 . The same can be said about sixths. Further the concept of why we calculate area as we do can be explored by overlaying the tile array with a clear grid of the same number of squares (i.e., for a $4 \times 6$ array, use a clear grid of $2 \mathrm{~cm}$ squares in a $4 \times 6$ pattern). Students are asked to describe the area of the grid.

In conclusion, there are implications for teaching in terms of what can be done to help children develop key multiplicative concepts in a connected way. The evidence presented here suggests that such pedagogical practices exist but may not be sufficiently widespread. Such teaching could include the following:

- Explicitly teach that the multiplicative situation is based on the number of equal groups and the size of each group.

- Develop an understanding of the terms factor and multiple through the use of arrays, and explicitly use them as 'mathematical language'. 
- Teach multiplication and division simultaneously, not separately.

- Develop the commutative property through the use of arrays and physically show the ' $x$ ' rows of ' $y$ ' gives the same result as ' $y$ ' rows of ' $x$ '.

- Develop a rich understanding of the multiplicative situation through the proficiencies of problem solving and reasoning.

If teachers view multiplication and division as different ways of representing 'the multiplicative situation', rather than as separate entities, the links and connections between the ideas discussed in this paper can be made explicit for children. When those connections are clearly understood, ideas such as the inverse relationship and the commutative property become much easier to grasp. The multiplicative array is a powerful tool for developing those connections.

\section{REFERENCES}

Australian Curriculum, Assessment and Reporting Authority (ACARA) (2015). Australian curriculum mathematics Version 7.5. Retrieved from http://www.australiancurriculum.edu.au/Mathematics/Curriculum/F-10.

Barmby, P., Harries, T., Higgins, S. and Suggate, J. (2009). The array representation and primary children's understanding and reasoning in multiplication. Educational Studies in Mathematics, 70, pp. 217-241.

Burns, M. (2010). Snapshots of students' misunderstandings. Educational Leadership, February, 2010, pp. 18-22.

Carroll, J. (2007). Developing Multiplicative Thinking. Retrieved from http://makingmathsmarvellous.wikispaces.com/file/view/MultiplicativeThinking.pdf

Charles, R.I. (2005). Big ideas and understandings as the foundation for early and middle school mathematics. NCSM Journal of Educational Leadership, 8(1), pp. 9-24.

Clark, F. B. and Kamii, C. (1996). Identification of multiplicative thinking in children in grades 1-5. Journal for Research in Mathematics Education, 27, pp. 41-51.

Clarke, D.M., Clarke, D.J. and Sullivan, P. (2012). Important ideas in mathematics: What are they and where do you get them? Australian Primary Mathematics Classroom, 17(3), pp. 13-18.

Confrey, J. (1994). Splitting, similarity, and rate of change: New approaches to multiplication and exponential functions. In G. Harel \& J. Confrey, ed., The Development of Multiplicative Reasoning in the Learning of Mathematics (pp. 293-332). Albany, NY: State University of New York Press.

Confrey, J. and Smith, E. (1995). Splitting, covariation, and their role in the development of exponential functions. Journal for Research in Mathematics Education, 26(1), pp. 66-86.

Hurrell, D. and Hurst, C. (2016). One-to-one Interviews: A Powerful Lens into the Mathematics Classroom. Manuscript submitted for publication.

Jacob, L. and Mulligan, J. (2014). Using arrays to build towards multiplicative thinking in the early years. Australian Primary Mathematics Classroom, 19(1), pp. 35-40.

National Governors Association Center for Best Practices, Council of Chief State School Officers (NGA Center). (2010). Common core state standards for mathematics. Retrieved from: http:/ /www.corestandards.org/the-standards

Siegler, R.S., Duncan, G.J., Davis-Kean, P.E., Duckworth, K., Claessens, A., Engel, M., Susperreguy, M.I. and Chen, M. (2012). Early Predictors of High School Mathematics Achievement. Psychological Science, 23(7), pp. 691697.

Siemon, D., Beswick, K., Brady, K., Clark, J., Faragher, R. and Warren, E. (2011). Teacbing mathematics: Foundations to middle years. South Melbourne: Oxford University Press.

Siemon, D., Bleckly, J. and Neal, D. (2012). Working with the Big Ideas in Number and the Australian Curriculum: Mathematics. In B. Atweh, M. Goos, R. Jorgensen and D. Siemon, ed., Engaging the Australian National Curriculum: Mathematics - Perspectives from the Field. Online Publication: Mathematics Education Research Group of Australasia pp. 19-45.

Siemon, D., Breed, M., Dole, S., Izard, J. and Virgona, J. (2006). Scaffolding Numeracy in the Middle Years - Project Findings, Materials, and Resources, Final Report submitted to Victorian Department of Education and Training and the Tasmanian Department of Education, Retrieved from http://slideplayer.com/slide/231010/

Siemon, D., Izard, J., Breed, M. and Virgona, J. (2006). The derivation of a learning assessment framework for multiplicative thinking. Paper presented at the 30th Conference of the International Group for the Psychology of Mathematics Education - Mathematics in the Centre. Prague.

Sophian, C. and Madrid, S. (2003). Young childrens' reasoning about many-to-one correspondences. Child Development, 74(5), pp. 1418-1432.

Wright, V.J. (2011). The development of multiplicative thinking and proportional reasoning: Models of conceptual learning and transfer. (Doctoral dissertation). University of Waikato, Waikato. Retrieved from http://researchcommons.waikato.ac.nz/ 
Young-Loveridge, J. (2005). Fostering multiplicative thinking using array-based materials. Australian Mathematics Teacher, 61(3), pp. 34-40.

Young-Loveridge, J. and Mills, J. (2009). Teaching multi-digit multiplication using array-based materials. In R. Hunter, B. Bicknell, \& T. Burgess, ed., Crossing divides (Proceedings of the 32nd annual conference of the Mathematics Education Research Group of Australasia pp. 635-643). Palmerston North, NZ: MERGA 